\title{
Pac cidades históricas: análise da experiência de Congonhas sob a ótica do culto moderno aos monumentos ${ }^{1}$
}

\author{
Pac historical cities: analysis of Congonhas' experience from the perspective \\ of the modern cult of monuments
}

Alexandre Augusto da Costa ${ }^{A}$

${ }^{a}$ Docente do curso de Publicidade e Propaganda do Centro Universitário Presidente Antônio Carlos, (Unipac), Barbacena, mestre em Comunicação Social pela UFJF.

E-mail: llexxander@gmail.com

\begin{abstract}
Este artigo propõe um debate entre as ações do programa PAC Cidades Históricas do governo federal em investimentos e requalificação dos sítios históricos e do entorno urbano a partir da experiência nos últimos anos da cidade de Congonhas - MG, observando as conceituações do historiador austríaco Alois Riegl (2014) sobre o culto moderno aos monumentos. Congonhas guarda o Santuário do Senhor Bom Jesus de Matozinhos, reconhecido pela Unesco como patrimônio da humanidade (1985): a obra-prima do mestre barroco Antonio Francisco Lisboa (Aleijadinho) com os 12 profetas em pedra-sabão e as 66 esculturas dos passos da paixão de Cristo no conjunto da Basílica. Na segunda década do presente século a Prefeitura Municipal criou uma equipe de trabalho permanente para elaboração, captação, gerenciamento e execução das obras do programa do governo federal, que envolvem os principais prédios do período colonial e, de forma mais abrangente, o entorno da região da Basílica com intervenções de restauro e requalificação urbana. Nesse sentido, este trabalho busca pensar as categorias de Riegl (2014) sobre o "querer da arte" na modernidade como ponto central e, de forma preliminar, suscitar algumas discussões sobre o conceito de reflexividade de Henri-Pierre Jeudy (2005).
\end{abstract}

Palavras-chave: monumento, patrimônio, restauração, preservação, políticas de salvaguarda.

This article proposes a debate between the actions of the PAC program Historic Cities of the Federal Government in investments and requalification of historical sites and urban surroundings based on the experience in the last years of the city of Congonhas, state of Minas Gerais, Brazil, by observing the concepts of the Austrian historian Alois Riegl (2014) on the modern cult of monuments. Congonhas keeps the Sanctuary of Senhor Bom Jesus de Matozinhos, recognized by UNESCO as a World Heritage Site (1985): the masterpiece of baroque master Antonio Francisco Lisboa (Aleijadinho), with 12 prophets in soapstone and 66 sculptures of the steps of the passion of Christ in the whole of the Basilica. In the second decade of the $20^{\text {th }}$ century, the Municipality created a permanent work team for the elaboration, collection, management and execution of the works of the Federal Government program that involve the main buildings of the colonial period and in a more comprehensive way the surroundings of the Basilica region with restoration and urban requalification interventions. In this sense, this study seeks to think the categories of Riegl (2014) about the "wanting of the art" in modernity as a central point and, preliminarily, to raise some discussions about the concept of reflexivity by Henri-Pierre Jeudy (2005).

Keywords: monument, patrimony, restoration, preservation, safeguard policies. 


\section{INTRODUÇÃO}

Ao ser contratado pelo governo da Áustria em 1902 para fazer um inventário e construir as bases de uma política pública de preservação do patrimônio, o historiador Alois Riegl talvez não imaginasse que no decorrer de sua investigação construiria categorias de análise que inspirariam a proteção e salvaguarda do patrimônio, sobretudo nos países da Europa e da América Latina nos séculos seguintes. As colaborações do historiador dedicadas à evolução histórica, aos valores de rememoração e ao culto moderno aos monumentos forneceram aos campos da pesquisa e da gestão pública um mapa precioso com indicações iconográficas e rotas que podem ser tomadas para a compreensão e gestão dos legados patrimoniais que são fruto das manifestações artístico-culturais de determinada época.

Como bem explica Carlos Ferreira de Almeida, ao longo dos séculos a palavra monumento sofreu metamorfoses. Derivada do verbo latino monere, de 'advertir, lembrar', este sentido do termo, como obra que lembra, se manteve durante a Idade Média, quando a "palavra 'moimenta' significava, sobretudo, uma construção tumular" (ALMEIDA, 1993, p. 411). De acordo com Alois Riegl (2014,p. 31), o que é central nas sociedades na constituição de um monumento é a busca pela imortalidade que se materializa por meio da arte ou da escrita. Riegl profetiza que a criação e conservação dos monumentos volíveis (aqueles feitos com a intenção de atravessar outras temporalidades) se encontram nas mais remotas épocas da cultura humana - o que pode ser verificado até os dias atuais. Neste sentido, o monumento atuaria como âncora em que se firmaria a memória das pessoas, das sociedades ou de um povo, como indicadores de identidade e de classificação - ou lugar de memória.

Mas o teórico faz questão de reforçar que a preocupação principal do seu trabalho não é abordar a conservação e o culto moderno dos monumentos volíveis, mas sim aos monumentos históricos e artísticos. Afinal, o que é artístico e o que é histórico? Com a intenção de esclarecer esta questão, pontua que a "[ [...] obra de arte é toda criação humana tangível, visível ou audível, que apresenta valor de arte; sendo monumento histórico toda obra de constituição análoga que possui valor histórico" (RIEGL, 2014, p. 32).

De forma a esclarecer este problema, o teórico afirma que todo monumento de arte, sem exceção, é ao mesmo tempo também uma construção histórica, já que em determinada escala na evolução das artes plásticas - a rigor - não encontra um substituto equivalente (RIEGL, 2014). Inversamente proporcional, podemos considerar que "todo monumento histórico é também um monumento de arte", pois mesmo um escrito banal, como um pedaço de papel com uma curta nota sem muita importância, contém um valor histórico no que diz respeito à evolução técnica da fabricação do papel, do desenvolvimento da escrita, dos materiais e recursos usados para a execução da escrita etc. Esta concepção veio a partir do século 15, na Itália, quando as obras da Antiguidade começaram a ser reconhecidas mais pelas características artísticas e históricas e não apenas por representarem símbolos dos feitos da Grécia ou de Roma. Françoise Choay (2001) relembra que nesta época o homem ainda não tinha descoberto as grandes navegações, então não tinha uma relação com o futuro, com o novo e nem com o passado. Essa percepção veio muito depois, após inaugurada esta etapa geográfica e mercadológica.

Nestas novas rotas é que surge o valor de rememoração, que deixa no caminho - sem abandonar totalmente aquela ligação à memória coletiva e segue nutrindo o leito de um terreno histórico-artístico. Ao resolver este enlace, Riegl (2014, p. 33) propõe uma nova reflexão ao indicar que estes conceitos não são paradoxais, mas se entrelaçam em uma perspectiva que antes inclui, não exclui. Pensando desta maneira, o monumento possuiria, além do valor artístico, uma qualidade histórica, tornando-se histórico-artístico.

A modernidade teria inaugurado, então, nesta perspectiva, um novo tipo de culto aos monumentos, muito mais ligado ao valor que lhe é atribuído. Esta veneração estaria diretamente relacionada à compreensão do Kunstwollen - querer da arte ou vontade artística de cada época.

\section{Oвjetivos}

O presente artigo tem por objetivo principal analisar as políticas públicas, em especial a experiência do PAC Cidades Históricas em Congonhas (MG) à luz das categorias de Riegl (2014) sobre o "querer da arte" na modernidade.

Como objetivos secundários, o trabalho propõe observar o processo de implementação destas políticas públicas, problematizar a inflação de patrimônios e o tipo de cidade que está sendo espelhada, utilizando como aporte teórico o conceito de reflexividade de Henri-Pierre Jeudy. 


\section{O CONCEITO DO CULTO MODERNO AOS MONUMENTOS}

Na obra $O$ culto moderno aos monumentos (2014), Alois Riegl estabelece alguns dos preceitos para a compreensão e desenvolvimento do olhar contemporâneo para os valores de memória, a saber: 1. valor de antiguidade; 2. valor histórico; e 3. valor volitivo da memória.

O primeiro ponto é fruto das transformações do "valor histórico" (que se transfigurou do individual, insolúvel) ao coletivo e modificou-se em "valor evolutivo". "Esse valor evolutivo é o valor de antiguidade, que conhecemos há pouco e que pode ser definido como o produto lógico do valor histórico que o precedeu quatro séculos atrás" (RIEGL, 2014, p. 44). Esta aproximação denota que a existência do valor de antiguidade é uma consequência do valor histórico. Se o segundo valor foi predominante no pensamento europeu do século 19, o primeiro despontou como a principal preocupação do século 20 .

Já no valor de antiguidade, o monumento é interpretado como um objeto dinâmico (orgânico), que traz em si o desgaste natural das marcas do tempo e das forças da natureza. Este valor reforça os contrastes, as diferenças que podem ser percebidas, não apenas pelos estudiosos ou por pessoas de classes mais instruídas, mas também pelas massas. $\mathrm{O}$ valor faz também uma contraposição com o tempo presente e se mostra como algo incompleto, talvez por certa inclinação à dissolução da forma e da cor. Rejeita toda e qualquer ação interventora na conservação ou restauração que tente ir contra o desenrolar das leis naturais da natureza. Essa posição de não-intervenção, porém, se excetua em casos de ameaças de uma destruição violenta, seja pela ação do homem ou da natureza. Este posicionamento "maduro" da relação com o monumento é considerado, no entendimento de Riegl (2014), um traço da modernidade, um ícone da emancipação do indivíduo.

O historiador, porém, reconhece que no século 19 a apreciação ao máximo do valor histórico se constituiu como uma proteção legal aos monumentos. No segundo pressuposto teórico (valor histórico), "expande-se o círculo com a inclusão das obras que indicam um determinado momento, mas cuja escolha foi resultado da nossa vontade subjetiva" (RIEGL, 2014, p. 39). Este conhecimento, no entanto, dificilmente alcança as massas, limitando-se aos especialistas, conhecedores da história da arte. O monumento é compreendido neste conceito como testemunho de uma determinada época, de um certo estágio da evolução humana pertencente ao passado. Pelo fato de possuir esta dimensão documental, deve ser o mais fiel possível, ou o mais aproximado do momento da sua criação. Deve, portanto, ser preservado, de forma preventiva ao desgaste das forças naturais.

No centro da discussão está a prerrogativa de que o monumento deve ser intocável, mantendo os aspectos de autenticidade, para que, eventualmente, abra a possibilidade de se fazer uma restituição histórico-artística. Esta mimese, porém, é permitida desde que sirva para auxiliar a pesquisa científica, e não se propor como uma substituta da original com vistas à mera apreciação estética. Riegl, de maneira otimista, acredita que, no futuro, devido às possibilidades de técnicas de reprodução, as exigências da pesquisa histórica impulsionadas pelas novas descobertas tecnológicas possam ser satisfeitas pelo uso de "substitutos perfeitos dos originais" (RIEGL, 2014, p. 62).

Quanto aos momentos volíveis, são reconhecidas, na compreensão de Riegl, aquelas obras em que seus criadores manifestaram desejo de lembrar um determinado momento do passado, buscando a eternidade. Em outras palavras, a premissa fundamental dos monumentos comemorativos volíveis é a restauração - valor de atualidade. $\mathrm{O}$ historiador austríaco ressalta que estes anseios geralmente são amparados pela legislação que fornece os instrumentos legais para as intervenções. A fim de esclarecer estas distinções, Riegl coloca em uma mesma mesa, frente a frente, o valor volitivo de memória e o de antiguidade:

O conflito dessa classe de monumentos com o culto de antiguidade está dado a priori e de forma ininterrupta. Sem restauração, tais monumentos deixariam logo de ser volíveis e de existir. O culto de antiguidade é, portanto, desde o início, o inimigo mortal do valor comemorativo volível. (RIEGL, 2014, p. 64)

Este valor, no entender de Riegl, visaria sempre a integralidade das obras, de maneira a atenuar ou eliminar as marcas do desgaste natural do tempo. Porém, alerta que, cedo ou tarde, pode-se alcançar os limites destas interferências.

Os elementos valorativos da contemporaneidade estariam diretamente relacionados com dois tipos de necessidades do homem na visão de Riegl (2014, p. 66): 1. sensíveis: diz respeito aos valores práticos ou utilitários; e 2. especiais: compreende as demandas sensíveis ou 
espirituais. Esta última dimensão se divide ainda em: a) valor elementar ou de novidade - depende do estado de integralidade de uma obra recentemente concluída; e b) valor relativo: alicerçado na aceitação do Kunstwoollen (querer da arte) moderno.

Compreende-se por valores utilitários, nos aspectos sensíveis, aqueles que são de caráter funcional destinados a fins pragmáticos - sejam eles religiosos ou profanos. Em outras palavras, são elaborados para uma determinação de uso que não poderia encontrar um substituto para a mesma utilização. Estes valores estariam em permanente conflito com o de antiguidade. Nesta perspectiva, somente as obras sem utilidade poderiam ser apreciadas segundo o valor de antiguidade. A degradação ou desgaste natural do tempo poderiam ser vistas pela ótica contemporânea como algo que poderia incomodar o olhar, ao não apresentar o valor atual esperado (RIEGL, 2014, p. 68).Já o valor utilitário poderia colocar em colisão mesmo os argumentos dos defensores do valor utilitário, quando a não-interferência no desgaste natural de um monumento colocasse em risco iminente a vida das pessoas. Neste caso, a integridade humana deve ser prioridade.

A abordagem dos valores especiais do homem pressupõe que todo monumento tem um valor estético que seja capaz de atender às exigências do Kunstwollen moderno. Dito de outra maneira, deve-se assumir o compromisso de que os traços de degradação sejam eliminados, priorizando os aspectos originais da obra em forma e cor (RIEGL, 2014, p. 70). Este valor seria mais perceptível ao olhar do cidadão comum, componente das massas, pois traz em si a simbologia do vencedor, da superioridade do novo sobre o velho. Por outro lado, haveria uma vontade contemporânea, segundo Riegl, de se afirmar o presente sobre o passado. A visão moderna advoga não apenas que se mantenha a integralidade perfeita das formas e das cores das obras de outrora, mas também que se estabeleça uma distinção do estilo quanto às obras do presente em relação ao passado. Os monumentos contemporâneos necessitam ser os mais distintos possíveis no detalhamento e nas formas: o presente deve se sobrepor ao passado (RIEGL, 2014, p. 73).

\section{Os MONUMENTOS E A RELAÇÃO QUE ESTA- BELECEM COM A MEMÓRIA}

Não é precipitado dizer que o trabalho de Alois Riegl forneceu um importante norte na construção de uma certa consciência patrimonial nas sociedades ocidentais. Cabe ressaltar que durante mais de dois milênios - desde a Antiguidade até quase nossos dias a palavra patrimônio preconizava um conjunto de bens materiais, ou pertença de uma pessoa jurídica, indivíduo, casa ou instituição.

O aspecto contemporâneo da palavra patrimônio tem sua origem na Revolução Francesa. Carlos Alberto Ferreira de Almeida (1993) lembra que em meio à destruição, às pilhagens e deterioração dos bens da igreja e da monarquia, alguns políticos daquele tempo começaram a falar metaforicamente em proteger o "patrimônio artístico e monumental da nação" (ALMEIDA, 1993, p. 409).

Esse sentido foi se perdendo ao longo do século 19. Pensava-se muito em "monumentos históricos", em "monumento histórico" e pouco depois, em "monumentos nacionais" (ALMEIDA, 1993). Françoise Choay frisa que até a primeira década do século 20, patrimônio e monumento eram quase sinônimos, com uma maior predominância da ideia de pedra e cal (edificações). Essa conotação se modificou na década de 1960, mais precisamente a partir da Recomendação de Paris, em 1962, que ampliou o conceito de patrimônio cultural, estendendo-se à beleza das paisagens e sítios, rurais ou urbanos (IPHAN, 1962). Esta concepção passou a ser compreendida como uma "[...] herança que não para de aumentar, por via da anexação de novos tipos de bens e através do alargamento do quadro cronológico e das áreas geográficas no interior dos quais se inscrevem estes bens" (CHOAY, 2001, p. 12). Esta ótica foi ampliada pela atuação da Unesco na centralização das políticas internacionais de identificação e salvaguarda, sobretudo a partir da Conferência de Nairóbi, em 1976, que reforçou a preocupação da função dos conjuntos históricos e sua ambiência na vida contemporânea, e estabeleceu algumas diretrizes para se pensar o turismo (IPHAN, 1976).

É sempre válido salientar que a construção da identidade possui uma estreita ligação com a memória. Toda comunidade humana busca esta referência, substância fundamental da constituição do Patrimônio Cultural. Os monumentos são uma espécie de âncora em que se acorrenta o barco da memória. São eles que proporcionam segurança às comunidades e as permite a tranquilidade de se verem no presente e projetarem o futuro. Nesta abordagem, o patrimônio não deve ser observado apenas como uma reserva, nostalgia ou recordação do passado, mas também servir como um meio para compreender o presente - e integrar a vida contemporânea. A declaração 
de Quebéc ${ }^{2}$ (1984) também reconhece a importância da memória e chama a atenção dos governos locais para que coloquem à disposição e convoquem equipes de pesquisa multidisciplinar para melhor compreender e transmitir a "alma do lugar". Estes elementos nos permitem pensar, na contemporaneidade, nas políticas públicas desenvolvidas na cidade de Congonhas por intermédio do Programa de Aceleração do Crescimento - PAC Cidades Históricas, que será detalhado adiante.

Porém, o zelo e o entusiasmo muitas vezes podem fazer saltar notas desagradáveis da tessitura de memórias e provocar impasses ou certos tipos de violência que se estabelecem na imposição de uma suposta qualidade sobre outra. Os conceitos de Alois Riegl sobre o culto moderno aos monumentos, neste sentido, são essenciais para o entendimento da relação moderna da memória e da estética.

É o que denuncia Carlos Alberto Ferreira de Almeida quando faz uma dura crítica ao excesso de patrimonialização das gestões, sobretudo nacionais, denominadas por ele como "Complexo de Arca de Noé” - uma certa tendência contemporânea que causa impasses e estagnações, já que não se pode conservar tudo o que se tem interesse.

A mesma observância é anotada por Henry-Pierre Jeudy, em Espelhos da Cidade (2005). Neste trabalho, o historiador condena, nas gestões urbanas, o que chama de "reflexividade" - a tentativa de se criar uma equivalência geral com certas singularidades culturais. No entendimento do teórico, isso acaba criando simulacros, espelhamentos que miram sobretudo o passado, com olhos negligentes para o presente, provocando uma certa mortificação do que está vivo.

Em outras palavras, é como se a única saída para a afirmação cultural de uma cidade ou comunidade fosse a iniciativa de olhar-se no espelho, replicando enquadramentos de um mesmo objeto. O maior perigo desta tendência contemporânea das sociedades ocidentais é a cidade tornar-se um museu de si mesma na busca obsessiva por uma eterna identidade mantida por retoques de cirurgia plástica ou liftings.

Para Jeudy, a noção de reflexividade é um modo determinante de preservação da ordem simbólica de uma sociedade. Mas essa preservação, no entanto, se tornou mundial, "globalizada". O que interessa hoje é a forma pela qual um certo enquadramento simbólico assegura

2 Disponível em: https://bityli.com/9QaRE. Acesso em: 22 nov. 2020 a transmissão de sentido. A questão patrimonial se torna cada vez mais um problema de como se processa esta dinâmica. $\mathrm{O}$ enquadramento simbólico supõe uma determinada gestão das representações comuns de uma sociedade ou de uma cultura.

A gentrificação, que consiste na espetacularização dos espaços por meio da estandardização e a consequente expulsão (mesmo que indireta como consequência das intervenções da especulação imobiliária gerada por este processo) dos moradores nativos dos locais por outros de classes elitizadas é outro alerta importante que faz Jeudy (2005, p. 74). A nova paisagem urbana é composta por um apelo turístico das cidades que faz novas interpretações dos espaços, criando equipamentos sociais que se associam ao patrimônio local. Novos layouts são justapostos ao tecido urbano já presente, criando sobreposições em desenhos, estilos e técnicas de representar a identidade que acabam padronizando as representações e, por conseguinte, causam a gentrificação.

Ao trabalhar o contexto português de preservação, Almeida (1993) acredita que uma das saídas para uma melhor preservação é a tomada de consciência por meio do poder público e da comunidade local a respeito do patrimônio que possuem. Nesta perspectiva, somente o entendimento do patrimônio como substância primária permitirá que se desdobrem em cores secundárias que, olhadas em conjunto, podem formar o mosaico da memória coletiva ou a alma do lugar.

Presumimos que a gestão pública local possui, neste sentido, um papel central na classificação e gerenciamento dos patrimônios. Desta forma, este artigo propõe fazer um debate sobre a atuação da prefeitura de Congonhas na captação, gerenciamento e implementação dos recursos do Programa de Aceleração do Crescimento (PAC Cidades Históricas) do governo federal nos últimos anos. A cidade da região central do estado de Minas Gerais é polo econômico do Quadrilátero Ferrífero, detém as maiores empresas de mineração do país, como a Vale, CSN e Gerdau³,

3 Além do ICMS das mineradoras, é cobrada a Compensação Financeira pela Exploração de Recursos Minerais (CFEM) - uma das principais fontes de arrecadação do município de Congonhas. Após 10 anos de uma batalha que envolveu empresas mineradoras e governos municipais, foi sancionada em 19 de dezembro de 2017 e publicada no Diário Oficial da União a Lei 13.540/2017, que altera alíquotas da CFEM. Disponível em: https://bityli.com/ S9Y0J. Acesso em: 23 nov. 2020. 
e abriga na Basílica do Senhor Bom Jesus de Matozinhos a obra-prima do artista barroco brasileiro Antônio Francisco Lisboa (Aleijadinho), com os 12 profetas em pedra sabão e as 66 esculturas em cedro da Via Crucis. Em 1985, a Unesco concedeu a chancela de Patrimônio Cultural da Humanidade ao santuário.

A prefeitura de Congonhas criou, em 2013, uma equipe de trabalho permanente composta por técnicos em diversas áreas da administração pública ${ }^{4}$ para elaborar, submeter, captar e executar obras de restauração e de requalificação dos monumentos e sítios históricos. Os recursos adquiridos no programa PAC Cidades Históricas do governo federal são da ordem de R \$ 25 milhões ${ }^{5}$. Os detalhes dos recursos adquiridos e a atuação do grupo de trabalho de gestão do programa federal serão detalhados nos parágrafos seguintes.

\section{A EXPERIÊNCIA Do PAC CidAdES HistóRICAS EM CONGONHAS (MG)}

O PAC foi lançado em 2007 pelo governo federal e coordenado pelo Ministério do Planejamento com atenção especial na elaboração e execução de obras de infraestrutura social, urbana e logística. Em 2011 entrou na segunda fase e ampliou a parceria com estados e municípios. No ano de 2013, o Ministério do Planejamento, em parceria com universidades, governos municipais e a Caixa, criou uma linha específica de atuação centrada nos sítios históricos protegidos pelo Iphan: PAC Cidades Históricas. Os recursos do programa são liberados pelo Iphan à medida que os projetos são aprovados e as obras executadas pelas gestões municipais.

O PAC Cidades Históricas está sendo implantado em 44 cidades de 20 estados da federação. Ao todo foram selecionadas 425 obras de restauração de edifícios e espaços públicos com um investimento de

4 A equipe é composta pelo secretário de Planejamento e coordenador, Antônio Odaque da Silva, a secretária de Obras da cidade, Rosemary Aparecida Benedito, o diretor de Patrimônio Histórico, Luciomar Sebastião de Jesus que é também escultor e pintor - além de dois arquitetos, três engenheiros civis, uma advogada, dois economistas e um urbanista.

5 Disponível em: https://bityli.com/hvKNn. Acesso em: 23 nov. 2020.
$\mathrm{R} \$ 1,6$ bilhão ${ }^{6}$. Em Minas Gerais foram aprovados investimentos nas cidades de Belo Horizonte, Diamantina, Mariana, Ouro Preto, Sabará, São João del-Rei, Serro e Congonhas. Na Cidade dos Profetas de Aleijadinho foram selecionados 10 projetos de intervenção no restauro de bens históricos com um total de $\mathrm{R} \$ 25,08$ milhões, como detalharei adiante. É importante ressaltar que o fato de ter a chancela de Patrimônio da Humanidade não garante por si própria a captação e implementação das obras. Os recursos somente são liberados após a aprovação dos projetos e de acordo com o andamento da execução das obras ${ }^{7}$.

Antes de adentrar na análise da captação e efetivação dos recursos do PAC Cidades Históricas em Congonhas, cabe destacar que a cidade recebeu outros investimentos importantes em projetos de requalificação urbana que buscaram estabelecer um diálogo entre os sítios históricos e o centro do município como: a reforma e modernização da Praça JK, que interliga as igrejas da Matriz e do Senhor Bom Jesus; e a construção do moderno Museu de Congonhas (centro de referência em educação patrimonial) que fica localizado entre a Basílica e a Romaria. O Museu é de iniciativa da Prefeitura de Congonhas, que utilizou recursos próprios e outros captados pela Lei Rouanet, em diálogo com o programa Monumenta, do Iphan, e buscou o patrocínio do BNDES (Banco Nacional de Desenvolvimento Econômico e Social), CSN (Companhia Siderúrgica Nacional), Vale, Gerdau e o Banco Santander.

O espaço ${ }^{8}$ funciona como "museu de sítio", fazendo a mediação entre o Santuário e o público e busca qualificar a experiência de visitação ao intensificar os sentidos e a percepção, seja por meio de descrições, interpretações ou da criação de condições favoráveis

6 Disponível em: https://bityli.com/xumlU. Acesso em: 23 nov. 2020.

7 Disponível em: https://bityli.com/TEEfQ. Acesso em: 23 nov. 2020.

8 Inaugurado oficialmente em 15 de dezembro de 2015, o Museu de Congonhas está instalado em um edifício de 3.452,30 $\mathrm{m}^{2}$ e foi construído ao lado do Santuário, a partir de um projeto do arquiteto Gustavo Penna, vencedor de um concurso nacional. O edifício contempla em três pavimentos: sala de exposições, reserva técnica, biblioteca, auditório, ateliê, espaço educativo, cafeteria, anfiteatro ao ar livre e áreas administrativas. Disponível em: https://bityli.com/ KCa3F. Acesso em: 23 nov. 2020. 
à fruição. $\mathrm{O}$ museu ainda guarda a maior coleção de ex-votos do Brasil. O acervo que pertencia à colecionadora Márcia de Moura Castro e foi doado ao Iphan em 2011 é composto por 342 peças de devotos que manifestaram a fé na entrega de objetos como lembrança de uma graça alcançada. $\mathrm{O}$ espaço ainda abriga cópias em gesso de dois profetas (Joel e Daniel) - a partir de cópias em $3 \mathrm{D}^{9}$ destas e das demais esculturas em pedra sabão feitas a partir de um projeto de iniciativa da Unesco, que mapeou digitalmente as obras para garantir réplicas perfeitas caso as mesmas sofressem alguma deterioração grave ${ }^{10}$.

Após a descrição das principais e recentes intervenções da prefeitura municipal na malha urbana, adentremos na atuação da equipe de trabalho criada pelo governo local em 2013 para a captação, gerenciamento e execução das obras do PAC Cidades Históricas. Assim que foi criado, o grupo apresentou ao Iphan 27 projetos de intervenções que incluíam o restauro de elementos artísticos de igrejas coloniais,

9 Na proposta original do museu de Congonhas, cogitou-se a transferência completa dos 12 profetas em pedra sabão de Aleijadinho (em processo de degradação, com marcas de vandalismo e desgaste do tempo) e a substituição por cópias perfeitas. Porém, com o amadurecimento da discussão, optou-se por realizar as cópias para fins de pesquisas e estudos histórico-artísticos. Disponível em: https://bityli.com/ CqnyS. Acesso em: 23 nov. 2020.

10 Em 4 de junho de 2020 o BNDES aprovou projeto proposto pela Fundação Municipal de Cultura, Lazer e Turismo de Congonhas - FUMCULT para a confecção de réplicas de dez dos 12 profetas do Santuário do Bom Jesus de Matosinhos. Serão produzidos moldes de segurança dos profetas Isaias, Jeremias, Baruc, Ezequiel, Daniel, Oseias, Abdias, Amós, Habacuque e Naum. Até então só havia sido feita as réplicas de Joel e de Jonas, realizadas em 2011 pelo Instituto do Patrimônio Histórico e Nacional IPHAN e pela UNESCO. O projeto ainda contemplará a expansão do Museu de Congonhas, espaço anexo ao santuário inaugurado em 2015 com o apoio do BNDES. O museu, que pretende disseminar a importância da história local através do uso de recursos tecnológicos, construirá a Galeria dos Profetas. Ali serão expostas as réplicas dos profetas, de forma também a reunir o conhecimento na preservação de esculturas em pedra-sabão. Está previsto ainda no projeto o funcionamento de um anfiteatro para receber ações culturais complementares. Os recursos do BNDES serão utilizados, por fim, na estruturação de ações para melhoria da sustentabilidade financeira do Museu de Congonhas. Disponível em: https://bityli.com/A4eBv. Acesso em 23 de nov. 2020. a construção e a requalificação dos espaços públicos no entorno dos sítios históricos, em especial os pertencentes à área reconhecida pela Unesco como patrimônio da humanidade. No processo seletivo do Iphan participaram 44 municípios brasileiros com bens reconhecidos nacionalmente e mundialmente. Congonhas teve 10 projetos aprovados através da portaria do Iphan $\mathrm{n}^{\circ} 383$ de 20 de agosto de 2013 (ver tabela 1).

Tabela 1 - Projetos selecionados: portaria do Iphan $n^{\circ} 383,20 / 8 / 2013$.

\section{Restauração da Basília do Senhor Bom Jesus de Matozinhos \\ Restauração do prédio da antiga Câmara de Vereadores \\ Restauração do Cine Teatro Leon}

Restauração do Museu da Imagem e Memória

Requalificação da Alameda Cidade Matozinhos de Portugal

Restauração da Igreja Matriz de Nossa Senhora da Conceição

Restauração da Igreja do Rosário

Implantação do Parque Nacional Municipal da Romaria

Requalificação e reforma do Centro Cultural Romaria e Teatro

Requalificação do adro da Basílica do Senhor Bom Jesus de Matozinhos

Fonte: Arquivo da Secretaria de Planejamento da Prefeitura de Congonhas (2018).

Dos recursos garantidos do PAC Cidades Históricas, foram concluídas (ver tabela 2) e entregues em 2017 as obras de: requalificação da Alameda Cidade Matosinhos de Portugal ( $\mathbf{R}$ \$2,3 milhões); restauração da Matriz Nossa Senhora da Conceição ( $\mathbf{R} \$ 1.398 .370,69)$ com o apoio da Igreja católica e do MPF; e a reconstituição dos elementos artísticos da igreja de Nossa Senhora do Rosário, datada do século 17, no valor de $\mathrm{R} \$ 904.933,96$ pelo Iphan.

Em 2018 foram entregues as obras de restauração da Basílica do Senhor Bom Jesus de Matozinhos, com o aporte de $\mathrm{R} \$ 2,7$ milhões do governo federal (que transferiu a ordem dos recursos para o programa Agora é Avançar) e outros $\mathrm{R} \$ 492.931,42$ para o projeto da obra, por meio de um Termo de Ajustamento de Conduta do Ministério Público Federal. Todas as obras contaram com a colaboração da Igreja Católica e equipe técnica da Prefeitura Municipal, que acompanhou e orientou os trabalhos. 
Tabela 2 - Obras e ações concluídas.

\begin{tabular}{|c|c|c|c|}
\hline & $\begin{array}{c}\text { VALOR } \\
\text { UTILIZADO } \\
\text { (IPHAN) } \\
\end{array}$ & $\begin{array}{c}\text { APORTE } \\
\text { (complemento) } \\
\text { MUNICÍPIO }\end{array}$ & $\begin{array}{l}\text { VALOR } \\
\text { TOTAL }\end{array}$ \\
\hline $\begin{array}{l}\text { Elaboração de projetos restauração da Basílica do Senhor Bom Jesus de } \\
\text { Matozinhos }\end{array}$ & $56.712,89$ & & $56.712,89$ \\
\hline $\begin{array}{l}\text { Elaboração de projetos restauração do prédio da antiga Câmara de } \\
\text { Vereadores }\end{array}$ & $94.254,48$ & & $94.254,48$ \\
\hline Elaboração de projetos restauração do Cine Teatro Leon & $116.458,85$ & & $116.458,85$ \\
\hline Elaboração de projetos restauração do Museu da Imagem e Memória & $128.305,08$ & & $128.305,08$ \\
\hline Requalificação da Alameda Cidade Matozinhos de Portugal* - obra & $1.984 .847,50$ & $20.326,21$ & $2.005 .173,71$ \\
\hline Restauração da Basílica do Senhor Bom Jesus de Matozinhos* - obra & $2.277,338,61$ & & $2.277,338,61$ \\
\hline Restauração da Igreja Matriz de Nossa Senhora da Conceição* - obra & $1.378 .718,67$ & & $1.378 .718,67$ \\
\hline Restauração da Igreja do Rosário* - obra & $899.465,36$ & & $899.465,36$ \\
\hline
\end{tabular}

* Foi executada a restauração dos elementos artísticos integrados. Em elaboração projetos para utilização do saldo de recursos. Valor pactuado: valor previsto no termo de compromisso.

Valor IPHAN utilizado: valor efetivamente gasto ou utilizado até julho de 2018

Fonte: Arquivo da Secretaria de Planejamento da Prefeitura de Congonhas (2018).

Estão ainda em execução obras iniciadas no fim de 2018: a construção do Parque Natural Municipal da Romaria e o teatro Municipal (que está sendo erguido ao lado do mesmo espaço). Em 23 de novembro de 2020 foi entregue a obra de conclusão da restauração do prédio da Romaria, que foi transformado em centro cultural, abrigando museu, a Fundação Municipal de Cultura, Lazer e Turismo (Fumcult), e estúdios de rádio e TV educativa ${ }^{11}$. Já o projeto do adro da Basílica do Senhor Bom Jesus de Matozinhos, o Iphan assumiu a execução da obra que ainda está em fase de estudos devido aos problemas estruturais de declividade onde estão situados os profetas de Aleijadinho.

Há outras frentes importantes sendo lideradas pelo Ministério Público Federal. Além do Termo de Ajustamento de Conduta no valor de $\mathrm{R} \$ 492.931,42$ destinado ao projeto de intervenção e execução na obra de restauro da Basílica do Senhor Bom Jesus de Matozinhos, o MPF está custeando o projeto de intervenção e execução de serviço de desinfestação e imunização das esculturas de madeira da Via Crucis, como indica o Quadro 1.

Quadro 1 - Frente do Ministério Público Federal na capitação e destinação de recursos ao patrimônio de Congonhas.

Demais Informações: Existe um TAC PRMG/GB/MML

n 07/2017, firmado com o Ministério Público Federal e a empresa Anglogold Ashanti Córrego do Sítio Mineração S/A, para deselvolvimento das seguintes ações:

- projeto de intervenção e eexecução de obra de restauração do telhado da Basílica do Senhor Bom Jesus de Matozinhos (executada - valor $\mathrm{R} \$ 492.931,42)$.

- projeto de intervenção e execução de serviço de desinfestação e imunização das esculturas de madeira dos Passos da Ceia, do Horo, da Prisão, da Flagelação e Coroação de Espinhos, da Subida ao Calvário e da Crucificação de Cristo, localizadas nas seis capelas que compõem o Conjunto Arquitetônico, Paisagístico e Escultório do Santuário do Bom Jesus de Matozinhos.

O valor é R\$1.000.000,00, depositado em conta específica para o TAC, junto ao Fundo Profeta. Já foi transferido $\mathrm{R} \$ 600.000,00$.

Fonte: Arquivo da Secretaria de Planejamento da Prefeitura de Congonhas (2018).

11 Disponível em: https://bityli.com/qAebB. Acesso em: 23 nov. 2020. 
É importante ainda destacar a parceria do governo municipal na complementação de recursos do PAC das Cidades Históricas, como indica a tabela 3.

Tabela 3 - Projetos elaborados e obras complementadas com recursos do município.

Requalificação da Alameda Cidade

Matozinhos de Portugal (Projeto)

$80.389,93$

Implantação do Parque Natural Municipal

da Romaria (projeto)

$96.371,30$

Requalificação e reforma do Centro Cultural Romaria e Teatro (Projeto)

$345.108,50$

Requalificação da AlamedaCidade

Matozinhos de Portugal - (Obra)

$20.326,21$

Implantação do Parque Natural Municipal da Romaria - (obra)

$308.390,14$

Na continuidade das obras de requalificação urbana, como a realizada na Alameda Cidade de Matozinhos, teremos outra intervenção, que será realidada com recursos do município e passará pelas Ruas da Recordação e Alípio Barbosa, as quais tornarão os principais acessos ao Teatro da Romaria e ao Parque Natural Municipal da Romaria.

Fonte: Arquivo da Secretaria de Planejamento da Prefeitura de Congonhas (2018).

Como já destacado por Almeida (1993), os municípios possuem um papel fundamental na classificação e na gestão dos assuntos patrimoniais. Os contingentes destinados à elaboração e execução dos projetos e obras fornecem subsídios que nos permitem apontar que há um grande interesse da cidade na restauração e requalificação dos bens patrimoniais e espaços públicos, que não fica a depender apenas dos recursos garantidos pelo programa do Governo Federal ${ }^{12}$.

Esta conduta pode também revelar outras intenções, como a inserção do turismo como alternativa econômica nas próximas décadas, já que a cidade é ainda muito refém da matriz mineradora. Contudo é preciso um olhar mais distanciado para poder ver com mais clareza como se conformaram os contornos e contrastes da paisagem patrimonial. Neste sentido,

12 O fato de ser uma cidade mineradora, que arrecada recursos milionários como o ICMS e a CFEM, contribui para esta situação mais favorável. Em 2020 Congonhas, de apenas 50 mil habitantes, teve um orçamento aproximado de $\mathrm{R} \$ 500$ milhões. Disponível em: https://bit.ly/3cwuTbO. Acesso em 23 de nov. 2020. algumas perguntas saltam à superfície: como se estabelecem as relações com a memória? Quais valores do culto moderno aos monumentos são mais proeminentes? Estas são algumas das questões que tentarei esclarecer nos próximos parágrafos à luz das categorias de Alois Riegl (2014).

\section{Metodologia}

Como metodologia, este artigo realizou uma discussão acionando as categorias de Alois Riegl, a partir dos subsídios fornecidos pelos documentos levantados junto à Secretaria de Planejamento da Prefeitura de Congonhas e em matérias veiculadas no site oficial do governo local, no portal da Câmara Municipal e no portal virtual do Jornal Correio de Minas (de abrangência na Cidade dos Profetas), acerca da gestão municipal do PAC Cidades Históricas das obras já entregues ${ }^{13}$ e as que estavam em execução no ano de 2018. Mais precisamente, este artigo fará uma comparação das obras já concluídas (Alameda Cidade Matosinhos de Portugal; Igreja do Rosário ambas finalizadas em 2016; Matriz de Nossa Senhora da Conceição - 2017; elementos artísticos da Basílica do Senhor Bom Jesus de Matozinhos - 2018; do Centro Cultural da Romaria - 2020; e da construção que está em andamento, desde 2018, (Teatro Municipal) à luz deste teórico. Alguns aspectos sobre a reflexividade destacada de Henri-Pierre Jeudy (2005) serão suscitados nas reflexões finais deste artigo.

\section{As obras do PAC Cidades Históricas EM CONGONHAS (MG) SOB A ÓTICA DO CULTO MODERNO AOS MONUMENTOS}

Ligando a Romaria ao Santuário do Senhor Bom Jesus de Matozinhos, onde estão os 12 profetas em pedra sabão e as 66 esculturas em cedro do mestre do barroco Aleijadinho, a Alameda Cidade Matosinhos de Portugal recebeu recursos na ordem de $\mathrm{R} \$ 2$ milhões. A prefeitura entrou com um aporte de $\mathrm{R} \$ 20.326,21$ nas obras. A arquitetura se difere bem da colonial e

13 Será acrescentada a reforma das instalações do Centro Cultural da Romaria entregue em 23 de novembro de 2020. 
[...] contempla calçadas largas em quartzito e sem obstáculos que atrapalhem a caminhada; passarelas elevadas para travessia de pedestres; sinalização tátil auxiliando deficientes visuais; mobiliário urbano planejado e posicionado de forma adequada no ambiente; espaços de permanência; luminárias padrão; guarda-corpo em aço corten ${ }^{14}$; estreitamento de pista de carros, com objetivo de diminuir o tráfego de veículos devido à proximidade com o Santuário (JORNAL CORREIO DE MINAS, 2016) ${ }^{15}$.

Foram ainda realizadas obras do projeto luminotécnico, do sistema de irrigação, do paisagismo e da recomposição do muro da Romaria que havia cedido em uma tempestade há alguns anos. Nas conceituações de Riegl (2014) identificamos o valor volitivo de memória na ligação evidente do monumento com o presente, apresentando adequações que se encaixam no tecido urbano dinâmico. A recuperação do muro que sustenta parte da Alameda também indica caminhos neste sentido, já que os adeptos deste valor combatem a degradação trazida pela natureza e das forças destrutivas da ação humana. É possível também identificar o valor histórico (evolutivo), já que a arquitetura contemporânea busca criar um elo entre dois sítios históricos (Basílica - patrimônio da humanidade) e a Romaria. Por fim, o valor de arte é expresso na utilidade pública do espaço, ao privilegiar o pedestre em detrimento dos carros e proporcionar novos lugares de convivência.

A igreja de Nossa Senhora do Rosário é outra obra atendida pelos projetos municipais do PAC Cidades Históricas. Datada do final do século 17, é considerada pela Arquidiocese de Mariana o templo mais antigo de Congonhas. Foi erguida graças aos esforços das irmandades de N. Sra. do Rosário, São Benedito e Santa Efigênia. As obras de restauração custaram, com recursos do PAC, R $\$ 904.933,96$. A descoberta de uma verruma (instrumento de furação que lembra a pua) e dois malhos (ou macetes) foram atribuídas ao entalhador português Francisco Vieira Servas (1720-1811) pelo restaurador

14 Corten é um tipo de aço que possui em sua composição elementos que melhoram as propriedades anticorrosivas. Este tipo de aço é muito utilizado na construção civil e apresenta, em média, três vezes mais resistência à corrosão que o aço comum. Disponível em: https://bityli.com/ Txl6e. Acesso em: 23 nov. 2020.

15 Disponível em: https://bityli.com/PoQTh. Acesso em: 23 nov. 2020.
Geraldo Eustáquio Mendes de Araújo, que atua pela empresa Cantaria Conservação e Restauro, responsável pelas obras da igreja do Rosário. As ferramentas estavam localizadas pouco acima do entablamento, dentro do Arco do Cruzeiro, que é atribuído ao artista do século $18^{16}$.

As intervenções do Iphan por intermédio da prefeitura municipal se destacam pelo valor volitivo de memória com a preservação integral do monumento, visando a uma certa imortalidade do tempo em que foi erguida. $\mathrm{O}$ valor histórico também está presente, já que as restaurações buscaram mirar na autenticidade do lugar como um documento-monumento. A leitura dos elementos artísticos feita de maneira técnica pelo diretor de Patrimônio converge neste sentido.

Na Igreja Matriz de Nossa Senhora da Conceição, as obras foram na ordem de $\mathrm{R} \$ 1.398 .370,69$. Além do valor empregado, a prefeitura disponibilizou mão-de-obra especializada com equipes técnicas da Diretoria de Patrimônio Histórico, ligada à Secretaria de Gestão Urbana, da Secretaria de Planejamento e da Secretaria de Obras. As intervenções almejaram recuperar o suporte da Igreja e dos elementos artísticos. Podemos observar nas obras de restauração da Matriz, de maneira bem clara, à luz conceitual de Alois Riegl (2014), o valor volitivo de memória, que reage a qualquer degradação das forças da natureza e da ação do próprio homem. O Kunstwollen moderno está presente na recuperação e na perenidade estética do valor de novidade com vistas não somente à apreciação da igreja e ao congelamento das forças destruidoras da ação do tempo ${ }^{17}$, mas à utilidade do espaço (que recebe regularmente missas e cerimônias).

A restauração dos elementos artísticos da Basílica do Senhor Bom Jesus de Matozinhos (patrimônio

16 Disponível em: https://bityli.com/Vos4B. Acesso em: 23 nov. 2020.

17 No início desta década, a Igreja Matriz de N. Sra. da Conceição apresentava problemas arquitetônicos, no telhado, forro e outras partes do prédio. O Ministério Público, por meio do promotor de justiça, Dr. Vinícius Alcântara Galvão, conseguiu uma verba indenizatória de $\mathrm{R} \$ 76$ mil, oriunda de um Termo de Ajustamento de Conduta (TAC) que, somado à contrapartida da Igreja, possibilitou a elaborar o projeto estrutural. A Igreja custeou a pintura, a recolocação dos bancos $(\mathrm{R} \$ 120 \mathrm{mil})$, a sonorização $(\mathbf{R} \$ 80$ mil) e outras ações de melhorias que foram concluídas em 2014.Disponível em: https://bit.ly/ 3dhzUnR. Acesso em 23 de nov. 2020. 
da humanidade) custou cerca de $\mathrm{R} \$ 2.270$ milhões. A obra durou dois anos e meio e foi entregue dia 28 de junho de 2018. As intervenções se concentraram no restauro dos elementos artísticos da Basílica, pintura externa, recuperação de relicários e imagens, como a do Bom Jesus crucificado, localizado no altar-mor. Detalhadamente, uma matéria do portal da prefeitura descreve as obras:

Entre as ações realizadas, destaca-se a recuperação de uma pintura do século 18 nas laterais do camarim do retábulo-mor e simbologia do martírio de Cristo; os quadros da sacristia, nártex, coro e da nave; balaustradas; cimalhas; forros; retábulos laterais e da sacristia; arco do cruzeiro; púlpitos; pias; lavabo de pedra sabão da sacristia; e a cruz de Feliciano Mendes. Durante a obra, foram encontradas pinturas expressivas, como o fundo da pintura do forro da nave que era cinza liso e escondia um céu com nuvens e tonalidades do azul ao rosado e ainda uma pintura sobre tela na parte superior da Cruz, com a representação do Crucificado ${ }^{18}$.

É possível inferir, diante destas informações, que as obras de restauração se coadunam com o conceito de valor histórico de Alois Riegl (2014), já que o monumento e seus elementos artísticos foram resgatados no aspecto original, como um vestígio intocável do passado, visando permanecer o mais fiel possível ao aspecto original que foi manifestado no momento da criação. A identificação de um céu com nuvens que estava debaixo de uma camada cinza reforça esta argumentação. Também é possível reconhecer o valor de novidade, já que a restauração privilegiou o resgate da forma inalterada ou policromia pura dos elementos artísticos.

As obras que iniciaram em julho de 2018 a requalificação do Centro Cultural da Romaria e a construção do Teatro Municipal - têm um aporte de $\mathrm{R} \$ 1$ 19.330.610,38 com recursos do PAC Cidades Históricas. Deste montante, $\mathrm{R} \$ 6$ milhões foram destinados à recuperação do prédio da Romaria e outros cerca de $\mathbf{R} \$$ 3,3 milhões ao Teatro Municipal. A Romaria era utilizada como pouso para os romeiros que vinham a Congonhas nas festividades do Jubileu - festa religiosa de devoção ao Senhor Bom Jesus que possui mais de

18 Disponível em: https://bityli.com/16rJa. Acesso em: 23 nov. 2020.
250 de história. Foi construída no início do século 20 e nos anos 1960 foi vendida pela administração do Santuário a um grupo empresarial do Rio de Janeiro que pretendia construir um hotel. Da cúpula que formava o conjunto, após demolida, restaram apenas as duas torres principais. A prefeitura adquiriu o espaço em 1993 e contratou o arquiteto Sylvio de Podestá para a restauração do pórtico. Reconstruído em 1995, o prédio tornou-se um ponto de encontro e palco de realização de shows e eventos culturais, além de abrigar os museus de mineralogia e arte sacra, a sede administrativa da Fundação Municipal de Cultura, Lazer e Turismo (Fumcult) e uma rádio FM educativa.

Em dezembro de 2017 a prefeitura de Congonhas e o Iphan firmaram o Termo de Compromisso PAC $n^{\circ} 148$ no valor de $\mathrm{R} \$ 19.330 .610,38$ para a restauração e construção do Teatro Municipal (que inicialmente estava previsto no projeto original dos anos 1990 que não pôde ser construído). O arquiteto que reformulou o projeto é o mesmo que fez a primeira intervenção: Sylvio de Podestá. O Centro Cultural da Romaria, inaugurado em 23 de novembro de 2020, contém: o gabinete do prefeito, sala de reunião, sala multimeio, estúdio de rádio e TV educativa, administração da Fumcult, além de um bar-café, loja, museu de mineralogia e o memorial Matozinhos. Já o teatro Municipal está sendo erguido no paço que se encontra do lado de fora da cúpula.

A relação moderna com o valor de arte utilitário é talvez a mais evidente nas obras de restauração do prédio da Romaria e na construção do Teatro Municipal, já que as intervenções buscam, além de integrar os novos espaços de convivência ao sítio histórico, proporcionar uma nova dimensão de uso, que talvez possa potencializar o turismo da cidade ainda dependente na sua matriz econômica da arrecadação do ICMS e da CFEM das empresas mineradoras. $\mathrm{O}$ valor volitivo de memória está presente na ligação evidente do Teatro Municipal moderno de estrutura metálica - conectando-o ao presente, apresentando adequações que compõem o tecido urbano dinâmico. No Centro Cultural da Romaria o valor histórico também se destaca, uma vez que a integridade do sítio é preservada como uma espécie de história-documento.

\section{Resultados}

Destacamos que, a certa vanguarda da administração municipal de Congonhas nos projetos do PAC 
Cidades Históricas, tem sido reconhecida pelo Iphan. $\mathrm{Na}$ cerimônia da assinatura da ordem de serviço em 11 de junho de 2018 das obras de reconfiguração do Centro Gultural da Romaria e do Teatro Municipal a presidente do Iphan, Kátia Bogéa destacou:

Toda vez que venho aqui é um prazer e uma emoção. Congonhas, dentro do PAC Cidades Históricas, tem um diferencial em relação às outras 43 cidades que se inscreveram no programa. O prefeito e sua equipe, de forma diferenciada, contrataram todos os projetos e isso fez com que a cidade saísse à frente das outras. Por isso, temos os resultados", reforçou (PORTAL DA PREFEITURA DE CONGONHAS, 2018) ${ }^{19}$.

Ao mesmo tempo que há investimentos para o reconhecimento e identificação de valores históricos para se manter a integralidade dos monumentos (valor volitivo), ou mesmo a tendência ao se proporcionar o valor de uso visando o turismo, observamos que há uma total ausência da consciência do valor de Antiguidade e ainda um espaço reduzido de reflexões acerca dos impactos destas intervenções no entorno dos sítios históricos. Tem ocorrido um processo de gentrificação? Caso afirmativo, em qual medida? Como a comunidade local tem se apropriado do debate? - são possíveis perguntas que saltam à mente, mas que podem ser objeto de futuras reflexões em outras perspectivas teóricas e de campo.

Por outro lado, é possível inferir que há uma certa ambiguidade acerca da reflexividade na relação com a memória (JEUDY, 2005). A busca frenética por projetos de restauração pode talvez apagar a percepção do valor de Antiguidade, à medida que estes não compreendem o patrimônio como um mecanismo orgânico, sensível às alterações no tempo. Em outra medida, os esforços do governo municipal nos últimos anos consolidaram a expertise na captação e gerência da coisa pública, ao propiciar, nesta medida, novas oportunidades de negócios, especialmente para o turismo. Porém, todo esse incentivo - de forma intencional ou não - acabou por eleger uma identidade (dentre tantas outras possíveis, de município minerador, polo econômico, de tradições quitandeiras e de congados) ao fomentar a identidade

19 Disponível em: https://bit.ly/31wKpyl. Acesso em: 23 nov. 2020. cultural em torno do culto ao Senhor Bom Jesus de Matozinhos e do selo de Congonhas como Patrimônio da Humanidade.

Quanto à reflexividade das cidades contemporâneas, bastante criticada por Jeudy (2005), observa-se neste artigo uma dupla dimensão: por um lado, há uma tendência latente em enaltecer o passado colonial e a genialidade do mestre barroco Aleijadinho. Na ponta inversa é bastante clara a postura contemporânea dos projetos de integração e construção de novos espaços públicos construindo pontes com o passado, mas em novas perspectivas que demarcam uma distinção evidente da arquitetura colonial. Isso mostra, ao menos em certa ótica, que é possível olhar para o espelho da memória e criar projeções que podem se enquadrar em novas perspectivas da sociedade: nesta ótica o tempo presente também se afirmaria com uma nova estética. Estas tensões sobre a disputa da "alma do lugar" são descritas por Maria Lucia Bressan Pinheiro em "Trajetória das ideias preservacionistas no Brasil: as décadas de 1920 e 1930":

De resto, nada há de surpreendente na constatação de que a preservação do patrimônio é por excelência um campo de tensões, as quais, porém, se procura ignorar ou subestimar, a partir de conceitos naturalizados de memória, identidade e pertencimento. (2017, p. 30)

Com o intuito de problematizar estas relações, este artigo elegeu como ponto convergente as categorias de Alois Riegl, pensadas como ancoradouros ou plataformas para novos lugares de memória na perspectiva das políticas públicas contemporâneas. Ao articular estes conceitos com a experiência do PAC Cidades Históricas em Congonhas, averiguou-se uma expertise que foi desenvolvida nos últimos anos para a captação, administração de recursos e a construção de políticas públicas voltadas à preservação dos monumentos reconhecidos pela Unesco e no entorno histórico. A tentativa de construir uma plataforma econômica mais voltada ao turismo e diversa à mineração também se mostra como um caminho inescapável, diante dos grandes investimentos que estão sendo realizados no entorno dos sítios históricos. A dependência atual da mineração que gera empregos, arrecadação e move o caixa do município, reforça este direcionamento, já que por outro lado a atividade minerária usa recursos não-renováveis, ameaça a paisagem natural e causa 
problemas ambientais, sobretudo quanto à poluição ${ }^{20}$ e às barragens ${ }^{21}$.

Neste sentido, as políticas públicas cumprem um importante papel em promover a cidade e potencializar o turismo, e traçar alternativas de desenvolvimento sustentável. Porém, o poder público municipal e a comunidade de Congonhas precisam estar sempre atentos às consequências das interferências destas obras do PAC no espaço urbano, como foi ressaltado neste estudo. Mais precisamente, é necessário indagar a qualidade do diálogo do poder público local com os moradores nativos destas localidades e questionar se há, ou não, uma narrativa em torno da construção de uma identidade soberana que poderia apagar as memórias coletivas do almus loci.

As temáticas enfrentadas neste artigo envolvendo turismo, desenvolvimento local, preservação do patrimônio, memória, identidade e gestão são desafios imprescindíveis ao campo da academia e da administração pública. Propôs-se aqui adubar o solo destas discussões com a intenção de contribuir, de alguma forma, para as boas práticas da gestão pública em projetos e recursos e ainda no fortalecimento do debate em torno das pesquisas da história do tempo presente.

\section{REFERÊNCIAS}

ALMEIDA, C. F. de. Património: Riegl e hoje. Revista da Faculdade de Letras, Porto, v. 10, n. 2, p. 407-416, 1993.

CHOAY, F. A alegoria do patrimфnio. São Paulo: Estação Liberdade, 2001.

JEUDY, H-P. Espelho das cidades. Rio de Janeiro: Casa da Palavra, 2005.

PINHEIRO, M. L. B. Trajetória das ideias preservacionistas no Brasil: as décadas de 1920 e 1930 . Revista do Patrimqnio Histyrico e Arthstico Nacional, Rio de Janeiro, n. 35, p. 13-31, 2017.

RIEGL, A. O culto moderno aos monumentos: a sua essência e a sua origem. São Paulo: Perspectiva, 2014.

IPHAN. Recomendazxes de Paris. Rio de Janeiro: Iphan, 1962. Disponível em: https://bityli.com/9r3ON. Acesso em: 22 nov. 2020.

IPHAN. Recomendazxes de Nairybi. Rio de Janeiro: Iphan, 1976. Disponível em: https://bityli.com/9r3ON. Acesso em: 23 nov. 2020.

20 Os níveis de poluição do ar provocados pela atividade das empresas mineradoras preocupam moradores de toda a cidade. Com o objetivo de punir as indústrias que ultrapassarem os limites de emissão de poluentes recomendados pela Organização Mundial da Saúde (OMS), o Ministério Público Estadual e a Prefeitura de Congonhas por meio de uma parceria com recursos de um Termo de Ajustamento de Conduta (TAC) instalaram em 2017 a primeira de dez estações de monitoramento do ar na cidade. As empresas que infringirem os níveis de poluentes estabelecidos pela OMS serão penalizadas e pagarão multas de acordo com a legislação local. Disponível em: https://bit.ly/2Pfqzos. Acesso em: 23 nov. 2020.

21 A tragédias recentes em Mariana - MG (2015) e Brumadinho - MG (2019) causadas pelo rompimento de barragens de rejeitos de mineração mataram mais de uma centena de pessoas, milhares de espécies de peixes e aves e chamaram a atenção e preocuparam as comunidades locais, poderes públicos e pesquisadores do Brasil e do mundo todo. Em Congonhas a barragem da Companhia Siderúrgica Nacional (CSN) está localizada próximo ao bairro Residencial Gualter Monteiro e ameaça diretamente 1500 pessoas caso seja rompida. Disponível em: https://bit.ly/3m60K6y. Acesso em: 23 nov. 2020. 